\title{
E-Learning as a Stimulation Methodology to Undergraduate Engineering Students
}

\author{
http://dx.doi.org/10.3991/ijet.v8i3.2550 \\ Waleed Kh. Ahmed, Essam Zaneldin \\ United Arab Emirates University, Al Ain, UAE
}

\begin{abstract}
With the advances of the technology at the last decade, it becomes an essential for teachers to utilize recent advances in technology to enhance learning. Currently, educators are using different software and blended approaches to facilitate better class environments and make course material available to students anytime anywhere. This paper presents the diverse learning technologies used by the Faculty of Engineering at the United Arab Emirates University for teaching pre-engineering freshman students using Blackboard and classroom new technologies. Multiple approaches are adopted and presented in this paper to boost students' learning and make course material readily available for all students. These e-learning techniques were used to enhance the teaching of different courses at the foundation level of the faculty of engineering, basically Engineering Materials, Differential Equations and Engineering Applications and eventually Engineering Thermodynamic. Feedback acquired through the students, the result of utilizing the e-learning techniques showed interesting experience and improved students learning abilities.
\end{abstract}

Index Terms-Blended, e-learning, engineering, methodology, teaching, stimulation, undergraduate.

\section{INTRODUCTION}

With the rapid progress of the electronics and software during the past decades, it has become important and essential to teachers to utilize diverse technologies to attract and improve the students' skill with the existence of many distraction materials available nowadays through the internet using computers, mobiles and recently iPad and many other technologies. Since that time, teachers of different academic levels started using different software and blended approaches to create an easy class atmosphere and facilitate the leaning ways for the students and make it available and accessible any time using internet, but sometimes needs professional skills by means of certain software for creating animations or interactive videos. As a matter of fact, using animations has a significant impact on the students' understanding especially for sophisticated courses which need a tremendous amount of imagination by using basic animation techniques in PowerPoint presentations which provides an additional learning aid that support learning [1]. Moreover, it is suggested that increasing animation interactivity could significantly enhance students' achievement and improvement at the intermediate level of learning, in addition students confidence improvement and perception were not significantly impacted by the increase of animation interactivity [7]. It is well known that video tutorials are not a new concept [2] emerging in the late $1960 \mathrm{~s}$, since then, video modeling has been described as "instructional videos" or "video tutorials." [3]. In general, video tutorials are produced as an approach to promote guidance in developing new skills and abilities, for example, to improve teacher training [4] or to prepare medical students for their internship experience [5]. In addition, video tutorials have been used to evaluate the students' effectiveness in improving the learning efficacy [6]. Besides, it is reported that using Camtasia software has advantages and disadvantages as any other aspects, the advantages can be summarized [2]:

1. Teachers and students alike can gain from using and viewing video tutorials.

2. Students can have access to audio-visual explanation without having to attend a class.

3. Narrations can be written by the teachers with the specific purpose of guiding students to focus on forms or any certain items.

4. Camtasia offers teachers to deliver video tutorial resources to intensify students' exposure to the target materials.

In the other hand, the disadvantages of video tutorial are mainly Time consuming, because [2]:

1. Narration must be succinct, clear and appropriate for the targeted students.

2. Produced videos must follow consistency and developmental stages from easy to more difficult.

3. Video tutorials should have a revision segment as well as a lead into the next level.

4. Recording a perfect narration can require a lot of effort especially when considering speed and intonation.

Interactive multimedia animation with Macromedia Flash was adopted in teaching descriptive geometry [8] in order to accelerate the students learning process, therefore animations were developed that allow the interactive observation by the students of a selected topics. One of the most effective educational tools is virtual labs which provide a flexible and user friendly method to define the experiments to be performed on the mathematical model [9]. Students are permitted to design and perform their own simulation experiments which is consequently they become active players in their own learning process and this motivated them to learn. For mechanical engineering courses, virtual and remote laboratories for Automatics and Robotics course using Web-based experimentation tools was implemented which provides students a deep understanding of theoretical lessons [10]. Investigation the influence of interactive video on learning outcome and learner satisfaction in e-learning environments showed that using video in e-learning may not always be sufficient to improve learning [11]. Eventually, basic computer 
skills can be utilized to create a simple and inexpensive interactive pathology video which provides a supplement to conventional instructional methods and engaging the attention as well as the interest of medical students and pathology trainees and facilitating learning [12].

The present paper shows a blended teaching aids regarding using different software and techniques in teaching different courses in the Engineering Requirements Unit at the Faculty of the Engineering at the UAEU. Besides, Blackboard system as well as a personal website is used to spread the materials and make them available to all students. Mainly, three courses describe the contribution in term of using e-learning technologies: Differential Equations and Engineering Applications, Engineering Materials and Engineering Thermodynamic..

\section{DifFERENTIAL EQUATIONS AND ENGINEERING APPLICATIONS (MATH2210)}

One of the most challenges that instructors in the ERU face is teaching the differential equation and engineering applications course. Actually the course is divided into two major parts, the math part and the engineering part. In the engineering part, students usually practice the applications of the math part though many engineering topics and cases. In general, these applications include thermal, mechanical, civil and electrical systems which are basically taught in parallel with the syllabus of the math part. Moreover, students should practice using MATLAB as tool to solve the mathematical models established of each application. Mostly, engineering applications are considered one of the most fields that challenge students, therefore using the e-learning technology to overcome this obstruction with different styles. Two different types of tools are adopted, the interactive video system using Camtasia software, and the recorded video lecture utilized by the new campus facilities of the UAEU, besides to the saved lecture of SMART Notebook which belongs to SMART Technologies.

By using Camtasia software, PowerPoint presentation was converted to step by step interactive tutorial video which was very helpful to students in studying and understanding the electrical applications of the course, as a case study as shown in Fig.1, which illustrate an electric circuit that the students need to model it using Kirchhoff's current law to establish the mathematical model and then he state variable of the system of equations in order to be solved it by MATLAB.

Different interactive approaches were adopted, like using multiple choices; fill in the black and others as shown in Fig.2. The aim was to encourage students to depend on them self, besides the material provides continuous practice to those who face difficulties in understanding the topic.

The new campus of the UAEU supplies the state of the art technology in the class rooms, which is the SMART Board, Fig. 3.

This type of electronic boards offers different kind of capabilities. Notebook of this system allows to save notes written on the SMART Board and then can be saved at computers, besides graphics can be imported as well as text and clip arts and Adobe Flash. Moreover Notebook file can be exported in the form of HTML and PDF and even image file format. Moreover, the lecture itself can be recorded through the SMART video record feature availa- ble by the system. Accordingly, utilizing this technology was very powerful and helpful to teach the Mechanical system applications of the course as shown on Fig.4.

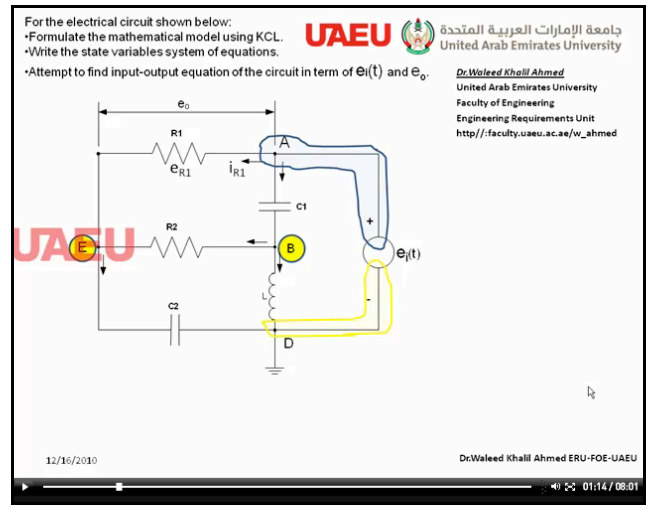

Figure 1. Shows the electrical studied case.

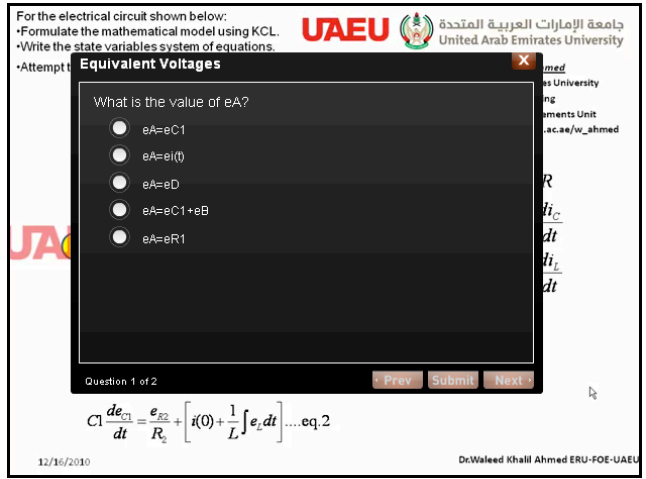

Figure 2. Interactive questions done by Camtasia software.

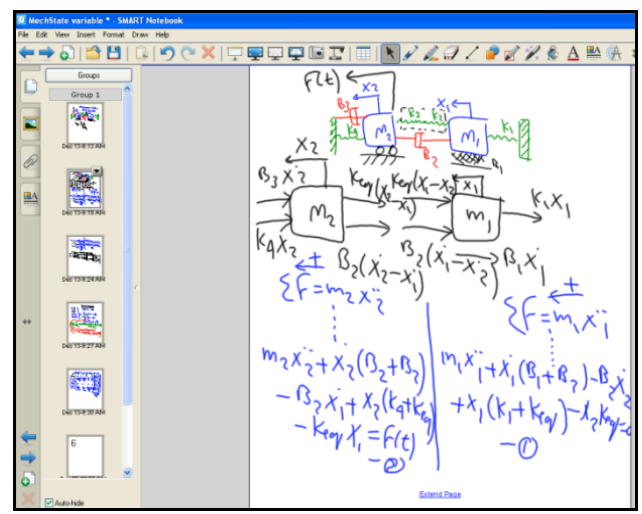

Figure 3. SMART Notebook screen of the SMART Board software.

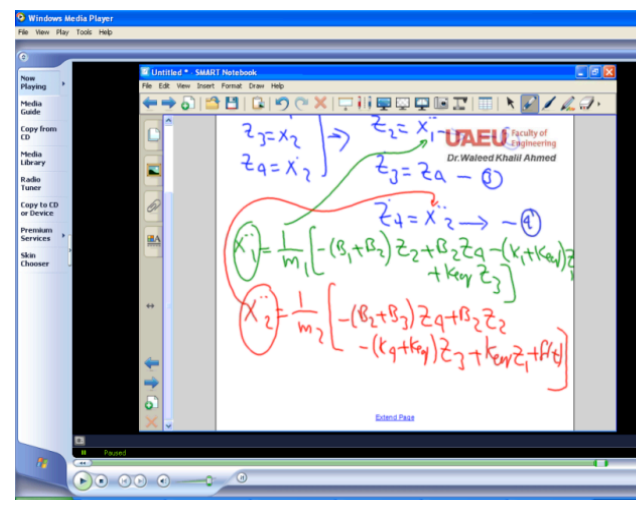

Figure 4. Video produced by SMART record. 


\section{ENGINEERING MATERIALS (MECH390)}

This course contains theoretical lectures besides to corresponding experimental procedures which mostly illustrate the concepts of some theoretical topics. The course material enriches with many physical, engineering and materials issues which basically need a virtual explanation before conducting the actual lab experiments. Unfortunately, previous editions of the text book [14] used were supported with CD that enables students to install it and get advantages of the supplied contents which basically includes some animations Fig.5, but recently the latest editions support a student learning recourses which is an online procedure that the students must go through to access materials interested.

Although it is considered as a significant step toward environmental issues, but it has some disadvantages regarding the registration procedure and many other concerns which make students frustrated and to give up using this service. So, using Blackboard and website, some of these materials were accessible easily to the students and they were encouraged to use them by showing them inside the classroom the way how to get access the material and use it. Previous attempts were done in the ERU using Adobe Flash to simulate virtually the essential experiments of the course, whereas Gif animations were used to illustrate some basic physical structures as shown in Fig.6.

\section{ENGINEERING THERMODYNAMICS (GENG220)}

One of the earlier difficulties that encouraged us to create some animation regarding complicated problems was this course. As a matter of fact, with the progress of the material of the course syllabus, students need to have a wide imagination mixed with some practical engineering knowledge which is considered rare in this level of the study, like as an example taking about moving piston cylinder system of an engine shown in Fig.7.

Accordingly, the simple beginning was using PowerPoint features to establish the required animation and then converting the presentation to Gif file by the Camtasia software. The present step was fascinating and simplified students' understanding to the material. It was recognized that students found these animations substantially and more effective, this is reflected and measured through the quizzes assessments.

Finally animations of illustrations may provide a greater impact on learning than simply using regular drawing if it is available for the problems studied.

\section{Personal Website}

By self-motivation and humble experience using Microsoft FrontPage, we could create a simple webpage that has attracted up to this moment 15650 visits up to this moment during since of its establishment [13] as shown in Fig.8.

Moreover, the website is easily accessible and can be found thorough any search engine using simple words "waleed uaeu", and anyone can get it at the first rank of the search results as shown in Fig.9.

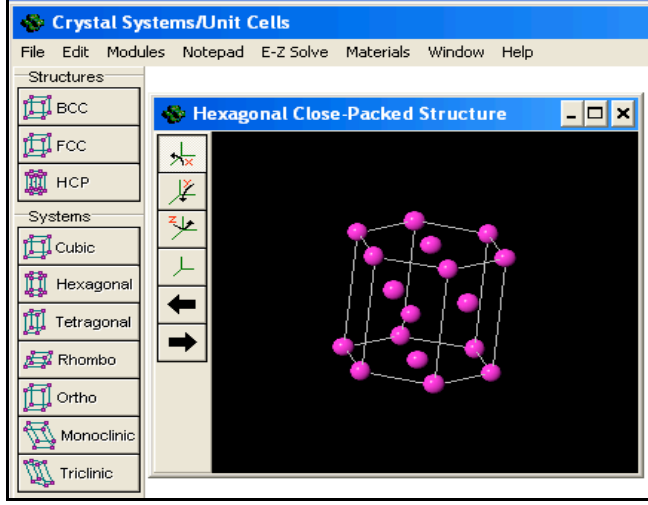

Figure 5. Animation of crystalline structure.

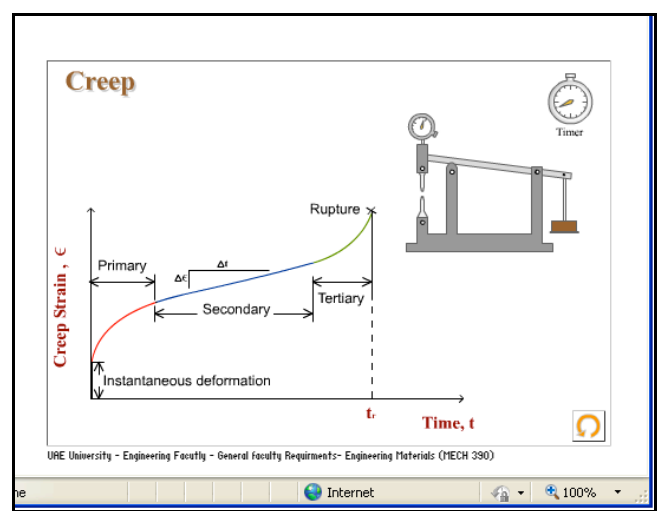

Figure 6. Virtual interactive experiment (creep test of materials)

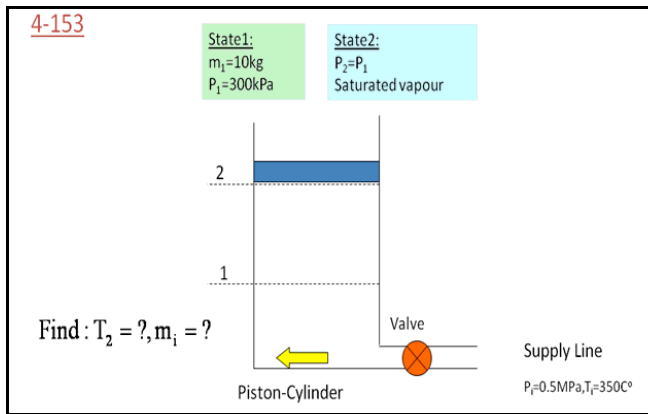

Figure 7. Upper represents the beginning of the piston movement, lower is final position of the piston.

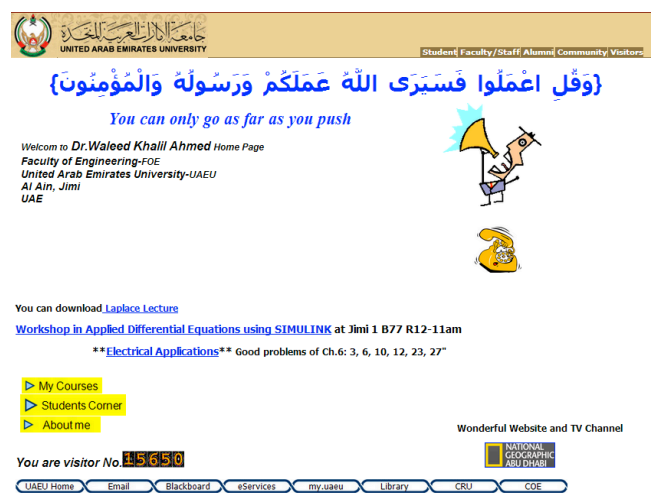

Figure 8. represents author's personal website 
PAPER

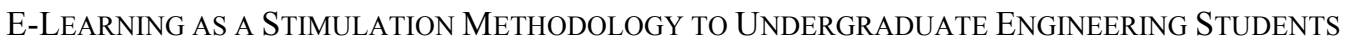

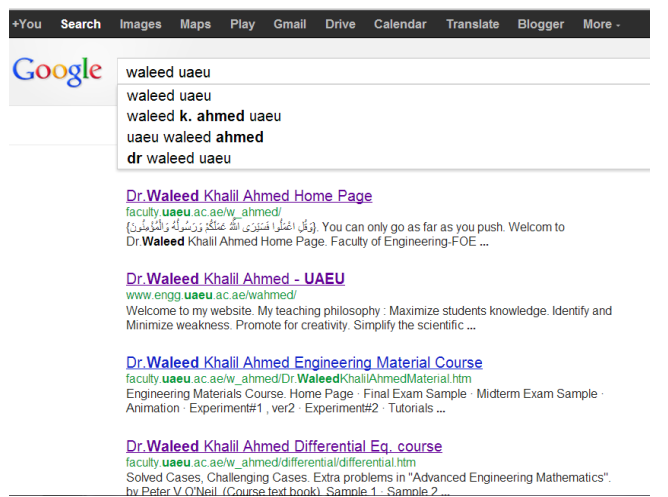

Figure 9. represents the rank of the website using Google search engine

\section{CONCLUSIONS}

Using blended technologies to teach and supply materials to students showed an impressive feedback, although this is not a new issue, but to launch it was not an easy task especially depending on own experiences. Moreover, knowledge of attractive materials can be available for everyone for the other sections which are not taught by me. The present experience clarifies the need of interactive materials as well to use diverse technology of teaching, but this needs training courses in addition to funding in this filed especially to the ERU to develop e-learning educational materials.

\section{REFERENCES}

[1] Scott T. Miller and C. Renee James, The Effect of Animations Within PowerPoint Presentations on Learning Introductory Astronomy, Astronomy Education Review, 10 2011, Vol.1, 010202, http://dx.doi.org/10.3847/AER2010041

[2] Nicolas Gromik, Video tutorials: Camtasia in the ESL classroom, The JALT CALL Journal, 2007, Vol.3, pp. 1-2.

[3] Hitchock, C. H., Dowrick, P. W. \& Prater, M. A., Video selfmodeling intervention in school-based settings: A review. Remedial and Special Education, 2003, Vol.24, 1, pp. 36-45. http://dx.doi.org/10.1177/074193250302400104

[4] Da Silva, M., Constructing the teaching process from inside out: How pre-service teachers make sense of their perceptions of the teaching of the four skills. Teaching English as a Second or Foreign Language, TESLEJ, 2005, Vol.9, 2, pp. 1-19.
[5] Lee, M. T., Jacobs, J. L., \& Kamin, C. S., Video-enhanced problem-based learning to teach clinical skills. Medical Education, 2006, Vol.40, pp. 459-489. http://dx.doi.org/10.1111/j.13652929.2006.02426.x

[6] Zhang, D., Zhou, L., Briggs, R. O., \& Nunamaker Jr., J. F. Instructional video in e-learning: Assessing the impact of interactive video on learning effectiveness. Information and Management, 2006, Vol.43, pp. 15-27. http://dx.doi.org/10.1016/j.im.2005.01.004

[7] Pei-Yu Wang, Brandon K. Vaughn, Min Liu, The impact of animation interactivity on novices' learning of introductory statistics, Computers \& Education, 2011, Vol.56, pp. 300-311. http://dx.doi.org/10.1016/j.compedu.2010.07.011

[8] Ramo'n Rubio Garci'a, Javier Sua'rez Quiro' s, Ramo'n Gallego Santos, Santiago Martı'n Gonza'lez, Samuel Mora'n Fernanz, Interactive multimedia animation with Macromedia Flash in Descriptive Geometry teaching, Computers \& Education, 2007, Vol.49, pp. 615-639. http://dx.doi.org/10.1016/j.compedu. 2005.11.005

[9] Carla Martin-Villalba, Alfonso Urquia, Sebastian Dormido, Development of virtual-labs for education in chemical process control using Modelica, Computers \& Chemical Engineering, Vol.39, 6 April 2012, pp. 170-178. http://dx.doi.org/10.1016/j.comp chemeng.2011.10.010

[10] Carlos A. Jara, Francisco A. Candelas, Santiago T. Puente, Fernando Torres, Hands-on experiences of undergraduate students in Automatics and Robotics using a virtual and remote laboratory, Computers \& Education, 2011, Vol.57, pp. 2451-2461. http://dx.doi.org/10.1016/j.compedu.2011.07.003

[11] Dongsong Zhang, Lina Zhou, Robert O. Briggs, Jay F. Nunamaker Jr., Instructional video in e-learning: Assessing the impact of interactive video on learning effectiveness, Information \& Management,2006, Vol.43, pp. 15-27. http://dx.doi.org/10.1016/j.im. 2005.01 .004

[12] John Woosley MD, PhD, Creating interactive pathology tutorials in QuickTime and Flash, Human Pathology, 2006, Vol.37, pp. 974- 977. http://dx.doi.org/10.1016/j.humpath.2006.03.012

[13] http://faculty.uaeu.ac.ae/w_ahmed/Default-old1.htm, accessed on March 10, 2013.

\section{AUTHORS}

Waleed Kh. Ahmed is with United Arab Emirates University, Engineering Requirements Unit, Al Ain, UAE.

Essam Zaneldin is with United Arab Emirates University, Civil Engineering Department, Al Ain, UAE.

Received 10 March 2013. Published as resubmitted by the authors 02 June 2013 . 